box system has been widely used; but it has been often proved difficult to set up and adjust. Modifications such as the cannulation of both nares ${ }^{2} 19$ have recently been described and make the system easier to use. Further trials are clearly needed of methods which do not require the high degree of medical and nursing skills and complex apparatus which the U.C.H. group have employed so successfully. What is required is a technique which can be set up quickly and easily in the special care unit of any maternity hospital.

1 Fedrick, J., and Butler, N. R., Biologia neonatorum, 1970, 15, 229.

2 Klaus, M. H., and Fanaroff, A. A., in Care of the High Risk Neonate. Philadelphia, W. B. Saunders, 1973.

Gluck, L., et al., American fournal of Obstetrics and Gynecology, 1971,

Condorelli, S., Cosmi, E. V., and Scarpelli, E. M., American fournal of Obstetrics and Gynecology, 1974, 118, 842.

5 Wagstaff, T. I., Whyley, G. A., and Freedman, G. A., Fournal of Obstetrics and Gynaecology of the British Commonwealth, 1974, 81, 264.

- Gluck, L., and Kulovich, M. V., American fournal of Obstetrics and Gynecology, 1973, 115, 539 .

7 Whitfield, C. R., et al., British Medical fournal, 1972, 2, 85.

8 Lemons, J. A., and Jaffe, R. B., American Fournal of Obstetrics and Gynecology, 1973, 115, 233.

Richardson, C. J., et al., American fournal of Obstetrics and Gynecology, 118, 1115-1118.

10 Bauer, C. R., Stern, L., and Colle, E., Pediatrics, 1974, 53, 7.

11 Liggins, G. C., and Howie, R. N., Pediatrics, 1972, 50, 515.

12 Spellacy, W. N., et al., American fournal of Obstetrics and Gynecology, $1973,115,216$.

13 Cohen, M. M., Weintraub, D. H., and Lilienfeld, A. M., Pediatrics, 1960, 26, 42.

14 Gluck, L., et al., Pediatric Research, 1972, 6, 81

14 Gluck, L., et al., Pediatric Research, 1972, 6, 81. 118.

16 Hobel, C. J., et al., Fournal of Pediatrics, 1972

17 Reynolds, E. O. R., and Taghizadeh, R., Archives of Disease in Childhood, $1974,49,505$.

18 Gregory, G. A., et al., New England fournal of Medicine, 1971, 284, 1333. 19 Caliumi-Pellegrini, G., et al., Archives of Disease in Childhood, 1974, 49, 228.

\section{Fourth, Fifth, and Sixth}

Scarlet fever, rubella, and measles are first, second, and third. Fourth, if it exists, is Filatow-Dukes's disease, fifth is erythema infectiosum, and sixth is exanthum subitum.

Fourth disease was carefully described by Filatow $^{1}$ in 1885 and by Dukes ${ }^{2}$ in 1900 . Strawberry tongue, desquamation, and albuminuria were among its features, so it may well have been an unusual form of scarlet fever. If it was a disease sui generis, it seems never to have recurred this century.

Fifth disease, though apparently uncommon in Britain, has been reported ${ }^{3}{ }^{4}$ frequently in localized outbreaks elsewhere. Its official name is erythema infectiosum, but it is also known in America 56 as "slapped cheek disease." The rash is most prominent on the cheeks, where it first appears as bright macules which finally run into one another: it does not rise above the malar bones nor run across the mouth, so the term "slapped cheek" is an apt descriptive one. The rash later comes out on the limbs and, very sparsely, on the trunk, but it is always less bright there: it has been described as lace-like, reticular, annular, or serpentine, but in truth it is rather nondescript. It persists for a week or ten days. Other symptoms are slight and vague-malaise, a few aches, or headache-and there are no after-effects. It occurs in sharp outbreaks, often in school children, its main age incidence being on the 2-14-year-old age group. The incubation period is around 4 to 14 days, it seems to spread by droplet infection, and it is probably a virus disease. Two recent cases in young children are described at p.466.

Sixth disease affects usually children between 6 months and 2 years of age. Its commoner names today are exanthem subitum or roseola infantum. It has also been called "three-day fever": this name is undesirable because it might lead to confusion with dengue, but it does draw attention to the main characteristic of the disease, namely fever, though this may last longer than three days. The fever comes on abruptly and the temperature may run at about $39-40^{\circ} \mathrm{C}\left(103-105^{\circ} \mathrm{F}\right)$ for three to five days. The infant often seems bright and alert in spite of this high fever, but occasionally an infant has a convulsion. When the fever subsides a rash appears, first on the upper trunk then spreading to the neck and limbs. It consists of fine pink macules which do not coalesce and are fleeting and easy to miss. Leucopenia is common after the first day, which suggests that this is yet another virus disease. It may occur in sharp outbreaks, ${ }^{7}$ but many infants seem to have the fever without the rash, and this may obscure the epidemic picture. One outbreak was described in a maternity hospital when the disease spread to nurses and parents, ${ }^{8}$ but normally this sudden exanthematous disease remains a roseola of infants.

\footnotetext{
1 Harries, E. H. R., and Mitman, M., in Clinical Practice in Infectious Diseases. Edinburgh, Livingstone, 1951

2 Dukes, C., Lancet, $1900,2,89$.

Ager, E. A., Chin, T. D. Y., and Poland, J. D., New England fournal of Medicine, 1966, 275, 1326.

Edelson, R. N., and Altman, R., fournal Medical Society of New fersey, $1970,67,805$.

Ager, E. A., in Communicable and Infectious Diseases, Ed. F. H. Top, and F. F. Wehrle, St. Louis, C. V. Mosby, 1972.

Marcy, S. M., and Kibrick, S., in Infectious Diseases, ed. P. D. Hoeprich, Hagerston, Maryland, Harper and Row, 1972.

Hagerston, Maryland, Harper and Row, 1972.
Clemens, H., fournal of Pediatrics, 1945, 26, 66.

8 James, Ursula, and Freier, A., Archives of Disease in Childhood, 1949, 24, 54.
}

\section{International Views on Alcohol and Traffic Safety}

The problem of the drinking driver was recognized very shortly after motor cars appeared on the road, and last month the sixth international conference on the subject took place in Toronto. Almost everywhere in the world recently the consumption of alcohol has risen, there are more alcoholics, and both the speed and density of traffic has increased, making the results of collisions more serious. The disappointing message delivered to 700 representatives from more than 30 countries was that (with the possible exception of the United Kingdom) legislative programmes have made no real impact on the problem.

There was much interest at the conference in the reasons why the dramatic savings in casualties in Britain which followed the 1967 Road Safety Act have not been sustained. Even Professor H. L. Ross of Denver, who was highly critical of the successes claimed by the Scandinavian countries for their legislation, acknowledged that the United Kingdom had achieved important results. His time-series analysis had suggested that the initial effect was due to the firm belief among drivers that they would probably be caught if they drove after drinking. Court cases had been publicized by the press, keeping the law at the front of the drinking driver's mind. More recently, thought Professor Ross, it seemed that British drivers had realized that the risk of detection was really very low and were starting to take risks again. Scandinavian experience (where drinking drivers comprise $10 \%$ of the prison population) suggested that the probability of detection was more important than the severity of the punishment. Automatic disqualification was an important deterrent, and countries which had automatic conviction at a given blood level achieved better results than those in which it was left to a court to decide whether or not an offence had been committed. The British practice of allowing a police officer 
to carry out a breath test if there had been an accident or a traffic offence, as well as on occasions where the driver appeared to have been drinking, was approved by $\mathrm{Mr}$. B. R. Carr of the Canadian Ministry of Transport. It was not clear to the conference why the British police were dissuaded from waiting at times and places where there had almost certainly been heavy drinking.

The number of road casualties in young people is disproportionately high, and there was much evidence that alcohol is playing an increasingly important role in this context. In Ontario, for example, the legal drinking age had been reduced from 21 to 18 in 1971 and there had since been a sharp increase in drinking driving offences in the age group 16 to 19 . Experience in the U.S.A. had been similar, and the representatives of the Transport and Road Research Laboratory in England showed that here, too, blood alcohol levels had risen more sharply among young drivers than old. The discussion on the education of the public was therefore of special interest. Radio and television were widely used in some countries, especially in the U.S.A. It was not easy to assess their impact, and the evidence that they were effective was not substantial. One pilot project from Edmonton, Canada, seemed to show that a concerted campaign directed at social drinkers could give a reduction in alcohol-impaired driving. Clearly much more work is needed on the costs and benefits of education, but it seems that any tightening up of the law in the United Kingdom should be accompanied by a vigorous publicity campaign-the degree of enforcement of the law by the police is often higher when it is accepted by the driving public.

The conference was also concerned with the effects of drugs other than alcohol on driving. Alcohol is one of the few drugs which can both be estimated accurately in both blood and urine and for which there is a fairly precise relationship between blood levels and pharmacological effects. With other substances analysis may be difficult or impossible, and there may be differences in absorption, binding, and half life. The synergism between alcohol and the tranquillizers and barbiturates makes the combination of alcohol and drugs specially dangerous. Cannabis is widely taken in the U.S.A., but its importance in producing road accidents seems not so great as that of alcohol: it impairs attention and perception but does not seem to have much effect on risk taking.

Reviewing methods of breath analysis, Dr. K. Dubowski of Oklahoma accepted the evidence of the British workers that the blood-breath ratio for alcohol is $10 \%$ higher than that used at present in converting breath figures to blood figures. Several instruments in current use give blood alcohol results which are too low unless they are calibrated directly against known alcohol concentrations. New, reliable instruments are available, depending on fuel cells, and some are small and portable. The inaccuracy of the Alcotest breathalyser at present used by the police in the United Kingdom (but not in Northern Ireland) was the subject of adverse comment.

It was not universally agreed that a distinction can be made between the social drinker and the frank alcoholic, but it seems probable that many drivers with blood alcohol levels greater than $150 \mathrm{mg} / 100 \mathrm{ml}$ are alcoholics. Most of them should be offered treatment or given long periods of disqualification from driving.

Britain has already had successes in curbing the activities of the drinking driver. The committee set up by the Minister for Transport under the chairmanship of Mr. F. A. Blennerhassett, Q.C. should be able to suggest ways of improving the law and its enforcement so that further progress may be made.

\section{Oral Contraceptives and the Liver}

Oral contraceptive medication carries a small but definite risk to health, the most widely recognized problems being an increased incidence of venous thrombosis, pulmonary embolism, and cerebrovascular accident. ${ }^{1}$ Impairment of liver function may also occur, but all these complications have probably become less common since the introduction of low-oestrogen formulations. Many natural and synthetic oestrogens and synthetic progestogens are known to impair hepatic handling of bromsulphthalein, ${ }^{2}$ those with the configuration of 17- $\alpha$ alkyl substituted 19-norsteroids with a phenolic A ring being most consistently implicated, and most oral contraceptives contain mixtures of a synthetic oestrogen and progestogen having this structure. Up to $40 \%$ of healthy women taking these preparations will show increased retention of bromsulphthalein after a single intravenous injection, ${ }^{3}$ and when the maximum excretory capacity for bromsulphthalein was measured using an intravenous infusion technique some impairment was shown in all users of a variety of highoestrogen preparations. ${ }^{4}$ A slight and reversible rise in the serum aminotransferases or alkaline phosphatase may occur in some women during the first few weeks after starting oral contraceptives, ${ }^{5}$ and larger doses used in the treatment of malignant disease may be associated with the development of jaundice, ${ }^{6}$ though this is extremely rare in women taking the pill in normal dosage. A few of these patients have some form of underlying liver disease, but generally no such abnormality is present.

Jaundice induced by oral contraceptives is usually preceded by some days of malaise, anorexia, and nausea, and it almost always develops within the first six cycles of treatment. ${ }^{7}$ There is no fever or sign of a hypersensitivity reaction, and apart from jaundice and sometimes slight hepatic enlargement physical examination is negative. Liver function tests show a raised serum bilirubin and often a moderate rise in the serum aminotransferases, 237 though occasionally these may be raised to more than 1,000 units. ${ }^{8}$ The alkaline phosphatase is normal or slightly increased. Liver biopsy usually shows centrilobular canalicular and intracellular bile stasis with focal hepatic cell necrosis and scanty inflammatory cell infiltration. Recovery occurs within two months of withdrawal of the drug, but occasionally cholestasis persists for longer. ${ }^{9}$

It has been known for some years that genetic factors play a part in the pathogenesis of the jaundice in the cases in which there is no underlying liver disease. Thus it has been reported in two sisters ${ }^{9}$ and it is more common in Chile and parts of Scandinavia, areas where cholestasis of pregnancy is also more frequent, ${ }^{2}$ than in Britain or North America. The genetic predisposition has been elucidated further in a recent study from Stockholm ${ }^{10}$ in which the clinical and family histories of 129 women with oral contraceptive-induced jaundice were compared with a matched control population taking oral contraceptives who did not develop jaundice. The jaundiced women had experienced pruritus and jaundice in pregnancy significantly more often than the controls and the patients' mothers and sisters also experienced pruritus more frequently during pregnancy than their controls. It was of interest that gallstone symptoms and cholecystectomy had been more common in the jaundiced group and their sisters than in their respective controls. A high incidence of gallstones $(51 \%)$ has also been reported in another series of patients with recurrent cholestasis of pregnancy ${ }^{10}$ and an increased incidence was found recently in the Boston Collaborative Drug Surveillance 